It may be the opinion of Jack et al that sections of formalin fixed decalcified bone marrow are morphologically unsatisfactory and technically more demanding to prepare, but others have contested this. ${ }^{4}$ We may add that as recipients of numerous consultation cases the standard of MMA embedding of bone marrow trephines is equally poor in many centres.

It is difficult to understand the final paragraph in the letter of Jack et al. Why, if immunocytochemistry is so easily applied to MMA sections, do they find it necessary to combine this technique with flow cytometric immunophenotyping? We doubt that many routine laboratories have access to such sophisticated technology, desirable though it may be. The aim of our article was to draw attention to the value of the bone marrow biopsy specimen in lympho proliferative disorders and to provide a balanced view of the different approaches. We trust that we have achieved this.

1 Johns L, Hand NM, Fish DCW, Miller KD Immunocytochemistry on methyl methacrylate embedded tissue. $\mathcal{f}$ Pathol 1992, 167:Suppl 154A

2 Wolf E, Roser $\mathrm{K}$, Hahn $\mathrm{M}$, Welkerling $\mathrm{H}$ Delling G. Enzyme and immunohistochemistry on undecalcified bone marrow biopsies after embedding in plastic: a new embedafter embedding in plastic: a new embedding method for routine application. Virchow

3 Frisch B, Bartl R. In: Resham GA, ed. Atla of bone marrow pathology. Dordrecht: Kluwe Academic Publishers, 1990.

4 Gatter KC, Heryet A, Brown DC, Mason DY Is it necessary to embed bone marrow biopsies in plastic for haematological diagnosis?

\section{Staging and follow up of patients with} lymphoproliferative disorder

As a haematologist who both reports marrow biopsy specimens and treats patients based on the results, I wholeheartedly agree with Drs Schmid and Isaacson that trephine biopsies are an integral part of diagnosis, staging and follow up of patients with lymphoproliferative disorders, and that adequate biopsy specimens in terms of size and processing, are essential. ${ }^{1}$

I find it less easy to accept their statement that marrow biopsy specimens are especially important (my italics) in the staging of Hodgkin's disease. In their own series of 158 patients only 14 (9\%) had marrow disease. Obviously this is of immense importance for those 14 individuals, but one wonders to what extent marrow disease might have been predicted in these patients. Specifically, were the 14 all stage IIIB/IVB, or did they have other features suggestive of marrow disease? I personally do not recall seeing a patient with apparent stage I or IIA Hodgkin's disease who subsequently turned out to be stage IV after marrow biopsy. This is not to suggest that these cases do not ever occur, but I suspect they are extremely rare.

I would be interested to know if the authors feel that marrow biopsy should be performed in every patient with Hodgkin's disease (in which case, by their own figures a lot of unnecessary biopsies will be done) or whether a more selected group should be biopsied.
1 Schmid C, Isaacson P.J. Bone marrow trephine biopsy in lymphoproliferative trephine biopsy in lymphoprolifer
Disease. $f$ Clin Pathol 1992;45:745-50.

\section{Professor Isaacson comments:}

Dr Stark is probably correct in pointing out that by using the term "especially important" with respect to the use of marrow biopsies in the staging of Hodgkin's disease we have slightly overstated our case. Perhaps this reflects our experience as histopathologists since we do in fact receive a staging marrow biopsy from every new case of Hodgkin's disease, a practice which is still strongly recommended. ${ }^{1}$

Our experience is similar to that of $\mathrm{Dr}$ Stark and others ${ }^{2}$ in that in the series of 158 patients to whom we referred, of the 14 patients $(9 \%)$ with marrow disease only one was clinical stage $2 \mathrm{a}$.

There is, however, another angle to this argument which we feel is important, if not especially important. We find that in a large percentage of patients without marrow disease as a result of Hodgkin's disease there is a variety of non-specific reactions in the marrow some of which, including leukaemoid hyperplasia and inflammatory changes, have been shown to indicate a poorer prognosis. ${ }^{3}$ Moreover, a hypoplastic bone marrow may raise a cautionary warning with respect to chemotherapy and/or radiotherapy effects.

As clinical staging improves less stress will probably be laid on the marrow biopsy but for the reasons outlined above we feel that a trephine biopsy of the marrow should continue to be a part of the staging process.

1 Schmoll HJ, Peters HD, Fink U. In Kompendium Internistische Onkologie Teil II. Springer Verlag. Berlin, 1986:113. 2 Bartl R, Frisch B, Burkhardt R, Huhn D, row histology in Hodgkin's disease: correlation with clinical factors. $\mathrm{Br} \Im$ Haematol 1982;51:345-60.

3 Frisch B, Lewis SM, Burkhardt R, Bartl R. In Beckenkammbiopsien, Klinisch interBeckenkammbiopsien, Klinisch
pretiert. Springer pretiert. Spring

\section{Sentinel and Bactec blood culture systems}

The report by Stevens and colleagues on the Sentinel (Difco) and Bactec (Becton Dickinson) blood culture systems is likely to be welcomed by many diagnostic laboratories. ${ }^{1}$ In a recent review of blood culture methods in the United Kingdom, the Bactec system was used by all but one of the 124 machine based laboratories. ${ }^{2}$ The introduction of the fully automated Sentinel system should therefore generate greater competition within the commercial market BacT/Alert (Organon Teknica), another automated blood culture system based on colorimetric microbial detection, also seems to compare favorably with the Bactec system. ${ }^{3}$ In addition, other fully automated systems are either available (Bactec 9240) or being evaluated (Vitek, Biomerieux).
Both the Sentinel and BacT/Alert trials were based on the inoculation of $5 \mathrm{ml}$ of blood per bottle. ${ }^{2} 3$ As there is a direct correlation between volume of blood cultured and microbial yield, ${ }^{4}$ Becton Dickinson has recently developed a high volume $(10 \mathrm{ml})$ resin based blood culture system-NR Bactec Plus (BP). In a large multicentre study, excluding paediatric patients, the BP system showed a significantly increased isolation rate over its $5 \mathrm{ml}$ non-resin Bactec counterpart. ${ }^{5}$ In our own limited prospective study of BP and Sentinel systems, BP showed similar advantages. Of 1148 fourbottle blood culture sets evaluated, 146 clinically significant micro-organisms were cultured: 96 isolates were detected by both systems, $44(30 \%)$ by BP alone, and six (4\%) by Sentinel alone.

In the United States clinical trials are planned to compare a high volume resin based BacT/Alert system with its Bactec counterpart (JA Washington, personal communication). We hope that the Department of Health will support similar trials in this country when new systems are available to compare with BP. RPD COOKE
CT JENKINS Department of Medical Microbiology, District General Hospital Eastbourne East Sussex BN21 2UD

1 Stevens M, Patel H, Wellers A, et al. Comparison of Sentinel and Bactec blood culture systems. F Clin Pathol 1992;45. 815-18.

2 Brown DFJ, Perry SF. Methods used in the United Kingdom for the culture of microorganisms from blood. $\mathcal{F}$ Clin Pathol 1992; 45:468-74.

3 Thorpe CT, Wilson ML, Turner JE, et al. Bac T/Alert: an automated colorimetric microbial detection system. $\mathcal{F}$ Clin Microbiol 1990 28:1608-12.

4 Washington JA, Ilstrup DM Blood cultures: Issues and Controversies. Rev Infect Dis 1986;8:792-802.

5 Kountz FP, Flint KK, Reynolds JK, Allen SD Multicenter comparison of the High Volume $(10 \mathrm{ml})$ NR Bactec Plus system and the Standard (5 ml) NR Bactec system. Diagn Microbiol Infect Dis 1991;14:111-18.

Dr Stevens comments:

As Messrs Cooke and Jenkins point out, and as is well documented, the amount of blood cultured and the presence of resin have been shown to increase the isolation rate of blood culture systems.

The Department of Health (Medical Devices Directorate) is intending to conduct a trial of the Bactec 9240 blood culture instrument using high volume resin-based media in comparison with the BacT/Alert system currently being used in the United Kingdom. BacT/Alert bottles designed for the inoculation of up to $10 \mathrm{~m}$. of blood which contain resin are not at present obtainable in the United Kingdom. We have been informed by the suppliers of BacT/Alert that such bottles will be available in 1993.

PS. I have taken the liberty of correcting a few spelling and nomenclatural errors in the letter from Drs Cooke and Jenkins.

In the United States, clinical trials are planned to compare a high volume resinbased BacT/Alert system with its Bactec counterpart (JA Washington, personal communication). We hope that the Department of Health will support similar trials in this country when new systems are available to compare with BP. 


\section{Notices}

Association of Clinical Pathologists Junior Membership

Junior membership of the Association is available to medical practitioners who have been engaged in the practice of pathology for a period of less than four years. Junior members are able to remain in this category for a maximum of six years or on the attainment of consultant status. The annual subscription is $£ 34$ for those resident in the United Kingdom and $£ 65$ for those overseas. The annual subscription may be claimed against tax.

Junior members receive the fournal of Clinical Pathology each month. Other benefits are reduced registration fees to attend ACP scientific meetings, all the documents regularly sent to full members of the Association including $A C P$ News, which has a regular column for juniors, and the twice yearly summary of pathology courses included in the ACP programme of postgraduate education. Junior members have their own representative body, the Junior Members' Group, which has a direct input to Council.

For Junior Membership apply to: The Honorary Secretary, Association of Clinical Pathologists, 221 Preston Road, Brighton BN1 6SA. (0273) 561188

\section{THE EPIC STUDY}

The largest pan-European point prevalence study of nosocomial infection in intensive care units (ICUs), the EPIC Study, took place on the 29 April 1992 in 1472 ICUs throughout 17 western European countries. The initial data already provide an international overview of nosocomial infection in the ICU, and the comprehensive results of the 10 000-patient EPIC Study database were presented at the 13th International Symposium on Intensive Care and Emergency Medicine in Brussels, on 24 March 1993.

The EPIC Study results will be submitted for publication in an international journal later this year. Each participating ICU will receive an individual unit report followed by an advance copy of the special report on the European results of the study which will be available to non-participating ICUs in due course.

For further information on the EPIC Study final results meeting, please contact the EPIC Study Co-ordinator, Medical Action Communications, Action International House, Crabtree Office Village, Eversley Way, Thorpe, Egham, Surrey, TW20 8RY, UK.
Sport-The Health Challenges (in association with British Olympic Bid 2000)

Date

Wednesday 23 and

Thursday 24 June 1993

Venue

Manchester Conference Centre, UMIST, Sackville Street, Manchester M60 1QD

\section{Fee}

24 hour delegate/Full day delegate/single day delegate rates available from

The Royal Society of Health

Civic Reception and Delegate Dinner (optional)

All Enquiries to:

Miss Dawn Scanlan, Conference Department, The Royal Society of Health, 38A St George's Drive, London SW1V 4BH

Tel: 071-630 0121 Fax: 071-976 6847

\section{The Leeds Course in \\ Clinical Nutrition}

7-10 September 1993

St James's University Hospital, Leeds

Speakers include:

Dr T van der Poll (New York)

Professor B Rowlands (Belfast)

Professor N Wald (London)

Professor R C Coombes (London)

Professor J Garrow (London)

Further details from:

Mrs Hilary L Helme

Department of Continuing Professional Education

Continuing Education Building

Springfield Mount

Leeds LS2 9NG

Telephone (0532) 333233

19th Annual Lukes Conference:

Diagnostic Approaches to

Lymphoproliferative Disorders

Monday to Friday

October 15-19, 1993

Sponsored by Scripps Clinic and Research Foundation

This course is designed for haematologists, oncologists, and pathologists who are involved in the histological diagnosis or clinical evaluation of patients with malignancies of the lymphopoietic system. The conference will be held at the Sheraton Grande Torrey Pines Hotel in La Jolla, California. The course will offer 27 credit hours of Category I CME credit.

For further information contact: Department of Academic Affairs, 403C, Scripps Clinic and Research Foundation,

10666 N. Torrey Pines Road, La Jolla, CA 92037.

Telephone: (619) 554-8556 Fax: (619) 554-6310

\section{Lung Pathology}

London, National Heart and Lung Institute, 26-29 October, 1993

A comprehensive course of lectures and practical hands-on microscopy sessions aimed at pathologists in training and consultant pathologists wishing to update their knowledge of lung pathology. Places are limited to 24 .

\section{Fee $£ 220$ (or US\$360)}

Programme and application form from Professor B Corrin, Pathology,

Brompton Hospital,

London SW3 6NP, UK.

Fax 071-3518435

(44-71-351 8435 if outside UK).

\section{One-day Meeting on Gene Therapy}

\section{Royal Society of Medicine} Tuesday 1 June, 1993

Main topics:

Prospects for human gene therapy, advances in the application of gene therapy for SCID, cystic fibrosis, muscular disease, haemophilia, haematological diseases, cancer. Ethics, timing, implementation . . .

Organised by:

Section of Pathology of the RSM.

Registration Information:

Miss Judy Cook, Sections Office, RSM, 1 Wimpole Street, London W1M 8AE Fax: 0713553197

\section{Corrections}

Our apologies are extended to Drs Cooke, Jenkins and Stevens for duplication of text in their submissions to the Correspondence section of the Journal (Sentinel and Bactec blood culture systems; $\mathcal{F}$ Clin Pathol 1993;46:286.

We also apologise to Drs Cooke and Jenkins for the inadvertent inclusion of unnecessary text in Dr Stevens' reply.

Owing to printers' errors, incorrect formulae were published in the ICSM recommendations for measurement of erythrocyte sedimentation rate; $\mathcal{F}$ Clin Pathol 1993;46: 198-203. Diluted blood ESR $\mathrm{mm}=$ (undiluted blood ESR $\mathrm{mm} \times 0.86$ ) -12 is the correct version. Whenever this formula is repeated throughout the text the multiplication sign should be read as $\mathbf{x}$. A correct version of the recommendations has now been reprinted.

We apoligise to Professor Stuart for any inconvenience caused. 